\title{
Informasi Sebaran Titik Panas Berbasis WebGIS untuk Pemantauan Kebakaran Hutan dan Lahan di Indonesia
}

\section{Hotspot Distribution Based on WebGIS for Forest and Land Fire Monitoring in Indonesia}

\author{
TAUFIK HIDAYAT ${ }^{\star}$, MUHAMMAD PRIYATNA, AHMAD SUTANTO, \\ ABY AL KHUDRI, ROKHIS KHOMARUDIN \\ Pusat Pemanfaatan Penginderaan Jauh - Lembaga Antariksa dan Penerbangan Nasional \\ Jl. Kalisari No.08, Pekayon-Pasar Rebo, Jakarta 13710 \\ Email: Ipntaufik@gmail.com
}

\begin{abstract}
The Remote Sensing Application Center - LAPAN has resulted in information on hotspot spreading. Availability of information monitoring the distribution of hotspots latest rapid, precise and accurate can improve the remote sensing application to support the management of forest resources and establish a monitoring system that is accountable and can be a reference in the organization of activities of forest fire control and land at the same time participate in managing, maintaining safety as well as the preservation of Indonesia's natural resources is sustainable. Given the importance of information and communication in disaster crisis management, efforts to facilitate the implementation of dissemination of hotspots distribution information to the wider community should properly be realized. One application is to develop a Web-based dissemination system Geographic Information System with Geonode application. The method used in this research is a prototype with open technology. Geonode can integrate that information to the layers with web mapping systems and the internet. The opensource geoportal system is built, the result of a combination of Django framework and Python programming language that is capable of providing dynamic spatial visualization interactively and connected to other electronic information networks. This Dissemination System can be used for decision makers in preparation of planning, development, monitoring, and response to an emergency disaster of forest and land fires in Indonesia, as well as a reference in the field of innovative technology and application of Geospatial information.
\end{abstract}

Keyword: hotspots, forest fires, emergency response, Geonode, dissemination, web applications

\begin{abstract}
ABSTRAK
Pusat Pemanfaatan Pengideraan Jauh-LAPAN telah menghasilkan informasi sebaran titik panas. Ketersediaan informasi pemantauan sebaran titik panas terkini yang cepat, tepat dan akurat dapat meningkatkan pemanfaatan penginderaan jauh untuk mendukung pengelolaan sumber daya kehutanan dan membangun sistem pemantauan yang akuntabel dan dapat menjadi acuan dalam penyelenggaraan kegiatan pengendalian kebakaran hutan dan lahan sekaligus ikut serta dalam pengelolaan, menjaga keselamatan serta kelestarian sumber daya alam Indonesia yang berkelanjutan. Mengingat pentingnya informasi dan komunikasi dalam penanggulangan krisis akibat bencana, maka upaya memudahkan pelaksanaan penyebarluasan informasi sebaran titik panas masyarakat luas dengan baik perlu diwujudkan. Salah satu pengaplikasiannya adalah dengan mengembangkan sistem diseminasi berbasis Web Sistem Informasi Geografis dengan aplikasi Geonode. Metode yang digunakan dalam penelitian ini adalah purwarupa dengan teknologi terbuka. Geonode dapat mengintegrasikan informasi tersebut dalam layer-layer sistem pemetaan web dan internet. Geonode merupakan sebuah sistem geoportal opensource gabungan antaran framework Django dan bahasa pemograman Python yang mampu menyajikan visualisasi spasial dinamis secara interaktif dan terhubung ke jaringan informasi elektronik lainnya. Sistem diseminasi ini dapat dipakai untuk pengambilan keputusan dalam persiapan perencanaan, pembangunan, pengawasan, dan respon terhadap keadaan darurat bencana kebakaran hutan dan lahan di Indonesia, serta sebagai referensi dibidang teknologi inovatif dan penerapan informasi Geopasial.
\end{abstract}

Kata kunci: titik panas, kebakaran hutan, tanggap darurat, Geonode, diseminasi, aplikasi web 


\section{PENDAHULUAN}

\subsection{Latar Belakang}

Bencana alam merupakan masalah serius untuk dalam kehidupan dan diseluruh dunia ${ }^{(1)}$. Bencana dapat disebabkan oleh cuaca ekstrim dan juga dapat disebabkan oleh ulah manusia. Salah satu bencana yang sering terjadi di wilayah Indonesia adalah kebakaran hutan/lahan yang sangat mengganggu dan merugikan baik dari segi ekonomi maupun ekologi. Dampak yang ditimbulkan dari kebakaran hutan/lahan dari segi ekonomi adalah hilangnya ribuan hektar hutan lahan yang merupakan sumber devisa. Dari segi ekologi kebakaran hutan/lahan menyebabkan terjadinya deforestasi dan degrasi fungsi hutan, memusnakan ribuan spesies hewan dan tanaman di dalamnya.

Badan Nasional Penanggulangan Bencana (BNPB) memprediksi, kerugian ekonomi akibat bencana kabut asap yang terjadi karena kebakaran hutan dan lahan di beberapa provinsi di Indonesia pada tahun 2015 bisa melebihi angka Rp 20 triliun. Kebakaran hutan dan lahan di Indonesia, yang kemudian menimbulkan bencana kabut asap, bukan yang pertama kali. Dalam 20 tahun terakhir, bencana serupa hampir setiap tahun terjadi(2). Dampak lain dari kebakaran hutan/lahan ini adalah gangguan asap kebakaran yang mengganggu kesehatan masyarakat. Sumatera dan Kalimantan didera oleh kebakaran hutan dan lahan yang menimbulkan polusi asap yang luar biasa.

Pada tahun 2015, kejadian tetap berulang dan lebih panjang. Banyak pakar memprediksi bahwa dalam periode El Nino (iklim kering yang berkepanjangan), kebakaran hutan dan lahan akan semakin panjang mendera kedua pulau ini termasuk dampak asap bagi masyarakatnya. Pada bulan september 2015 di beberapa tempat misalnya di Riau, indeks kualitas udara akibat kebakaran hutan dan lahan adalah antara 400950, di palangkaraya mencapai 2.550 pada akhir bulan september 2015. Angka 300 ke atas adalah angka berbahaya bagi kesehatan manusia, dan layak untuk menjadi status darurat ${ }^{(3)}$. Guna meminimalkan dampak dari kebakaran hutan/lahan tersebut, dilakukan pemantauan secara kontinyu hingga terjadinya kebakaran hutan/lahan dapat diketahui lebih dini. Salah satu pengaplikasiannya adalah dengan cara mengembangkan aplikasi pemetaan web untuk diseminasi informasi pemantauan sebaran titik panas yang akan berfungsi dalam mendukung kesiapsiagaan dan tanggap darurat bencana kebakaran hutan/lahan dan membantu untuk menentukan kebijakan terkait dengan dampak lingkungan akibat kebakaran hutan/lahan di Indonesia.

\subsection{Aplikasi WebGIS}

Program kegiatan pengembangan Sistem Informasi berbasis WebGIS di Pusat Pemanfaatan Penginderaan Jauh (Pusfatja), Lembaga Penerbangan dan Antariksa Nasional (LAPAN) menghasilkan dan mendukung penyediaan informasi spasial pemanfaatan penginderaan jauh dalam sektor kehutanan, antara lain berupa pemantauan sebaran titik panas (hotspots) harian, berbasis pada data utama satelit MODIS Terra/Aqua ${ }^{(4)}$. Informasi tersebut memiliki peran penting dalam penyelenggaraan penanggulangan bencana, terutama dalam mendukung dan mewujudkan kesiapsiagaan dan tanggap darurat bencana kebakaran hutan dan lahan di Indonesia.

Suatu informasi spasial yang telah dihasilkan oleh Pusat Pemanfaatan Pengindeaan Jauh agar dapat diakses oleh instansi lain maupun masyarakat perlu dibangun sebuah sistem Geospasial Data Infrastructure (GDI).

Untuk menjalankan sebuah sistem GDI maka dibutuhkan keahlian terkait Konfigurasi MapServer dan Geographical Information System (GIS) ${ }^{(5)}$, dan juga sebuah insfrastruktur sistem yang dapat digunakan untuk menyebarkan semua informasi tersebut yang berdampak memajukan ekonomi, kehidupan sosial, dan ketahanan sebuah regional dan negara(6). Dengan berkembangnya teknologi Informasi dan komunikasi, setiap instansi dan masyarakat yang memanfaatkan informasi pengolahan citra pasti membutuhkan perantara sebuah sistem berbasis web.

Aplikasi WebGIS adalah prosedur atau proses merancang, menerapkan, menghasilkan dan mengirimkan peta dalam bentuk digital melalui media world wide web (www), atau dapat juga diartikan, pemetaan web adalah istilah umum untuk melihat dan mengambil informasi spasial melalui media web atau internet. Komponen utama sistem pemetaan web adalah web map server dan web map client(7).

Pemetaan web telah memudahkan cara mendiseminasikan dan berinteraksi dengan informasi spasial. Sejumlah perangkat lunak SIG digantikan hanya oleh satu pusat server pemetaan web yang dapat diakses oleh semua orang yang terhubung dengan akses ke internet melalui peramban web, peta dapat diakses melalui perangkat yang terhubung ke internet dan membuat permintaan ke server untuk sebuah peta digital secara online.

\subsection{Tujuan Penelitian}

Tujuan utama dari penelitian ini adalah membangun dan mewujudkan sistem Diseminasi Informasi Geografis berbasis Web. 
Dengan sasaran agar informasi spasial sebaran titik panas tersebut mudah diakses melalui jaringan informasi elektronik dan berinteraksi melalui peramban web. Pengguna diharapkan dengan mudah mengakses informasi spasial sebaran titik panas yang disajikan lewat WebGIS, sehingga dapat digunakan untuk mendukung pengambilan keputusan dan langkah-langkah strategis spasial - temporal atau sebagai Spasial Decision Support System.

Adanya produk informasi spasial sebaran titik panas yang benar dan akurat serta terdiseminasi dengan baik dapat meningkatkan pemanfaatan penginderaan jauh untuk mendukungan dan mewujudkan kesiapsiagaan dan tanggap darurat bencana kebakaran hutan dan Iahan di Indonesia

\section{BAHAN DAN METODE}

\subsection{Aplikasi Geonode}

Teknologi perangkat lunak yang digunakan pada kegiatan ini adalah Geonode yang berstandar Open Geospatial Consortium (OGC). Geonode adalah sebuah sistem manajemen konten geospasial, sebuah platform untuk pengelolaan dan publikasi data geospasial. Ini merupakan proyek bersama software opensource yang lebih matang dan stabil di bawah antarmuka yang konsisten dan mudah digunakan yang memungkinkan pengguna untuk berbagi data dan membuat peta interaktif. Geonode merupakan project open source yang dikembangkan untuk medukung pengembangan Platform sistem informasi geografis berbasis web dan infrastruktur data spasial( ${ }^{(8)}$. Geonode didesain untuk dapat dikembangkan lebih lanjut dan dapat diintegrasikan pada platform yang telah ada dan dapat menjadi salah satu aplikasi simpul (node) dari infrastruktur data spasial (IDS).

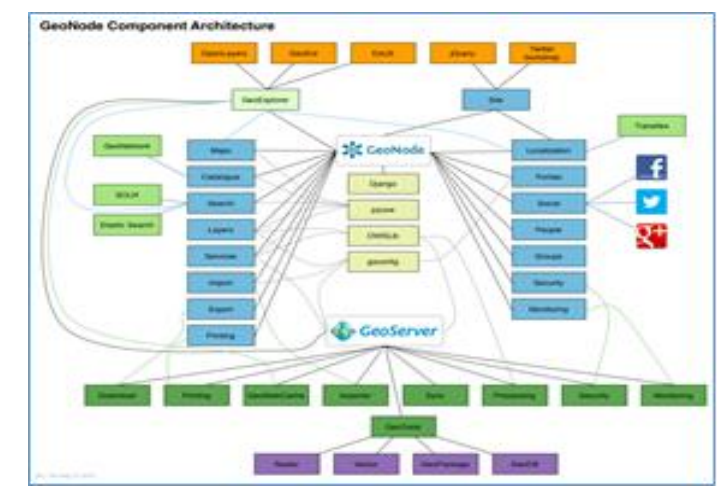

Gambar 1 Arsitektur Geonode

Geonode dibangun dari komponen project open source, yaitu: Django, pycsw, OpenLayers dan geoExt. Geonode mengimplementasikan standar OGC ${ }^{(9,10)}$. Komponen Geonode yaitu:

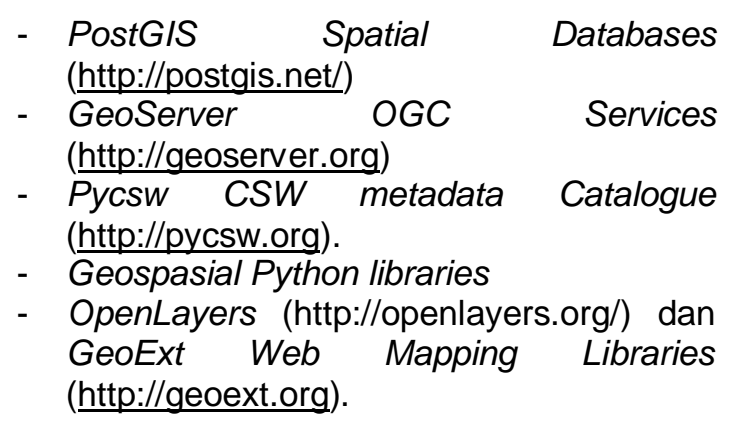

Geonode mengaplikasikan GeoServer sebagai aplikasi yang berfungsi sebagai layanan webGIS. GeoServer memungkinkan kita dapat mempublikasikan data dari berbagai sumber menggunakan protokol dan standaar dari OGC. Sistim Katalog dan meta data juga didukung oleh Geonode dengan mengaplikasikan pycsw sebagai katalog dan penyedia layanan metadata. Geonode mendukung services standar OGC yaitu:

$$
\begin{array}{ll}
\text { - } & \text { Web Map Service (WMS) } \\
\text { - } & \text { Web Feature Service (WFS) } \\
\text { - } & \text { Catalog Service for Web (CSW) } \\
\text { - } & \text { Web Map Context (WMC) } \\
\text { - } & \text { Tile Map Service (TMS) }
\end{array}
$$

Geonode dibangun menggunakan framework autentikasi dan terintegrasi dengan GeoServer ${ }^{(10)}$. Kepemilikan dan hak akses layer dan peta dapat digunakan untuk berbagi pakai data. Hak tersebut antara lain, read, write, dan melakukan perubahan terhadap hak akses. Data dapat disajikan secara terbuka kepada publik atau khusus untuk pengguna lain atau grup pengguna. Geonode memungkinkan pengguna untuk melakukan upload dan pengelolaan data spasial melalui web. Data spasial yang di-upload dapat dijadikan layanan web sesuai standar OGC yaitu WMS dan WFS ${ }^{(11)}$. Data spasial tersebut dapat tersedia dan dapat diproses oleh pengguna lain dalam membuat peta dan kartografi. Fitur yang didukung antara lain: GeoExtpoler client, editor kartografi, multi layer peta yang interaktif, dan dapat membagi dan menyertakan peta dalam web yang lain.

Geonode dapat berfungsi sebagai portal geospasial yang menyediakan penjelajahan dan pencarian data spasial. Geonode memudahkan dalan hal melakukan pencarian, visualisasi dan berbagai pakai data spasial.

\subsection{Data dan Informasi Titik Panas}

Pada penelitian ini, proses penyediaan data dan informasi tanggap darurat bencana kebakaran hutan dan lahan menggunakan data satelit penginderaan jauh, diantaranya:

- Data Terra/Aqua MODIS dan Suomi National Polar-orbiting Partnership 
(SNPP) pagi, sore, dan malam (Sumber dari PUSTEKDATA).

- Data Landsat (Sumber dari PUSTEKDATA).

- Data SPOT 6/7 (Sumber dari PUSTEKDATA).

- Data Lainnya yang mendukung (curah hujan, himawari, dan lain-lain).

Selain itu juga menggunakan perangkat lunak ArcView GIS 3.2, ENVI 4.8 dan ArcGIS 10.1, MODIS Swath, dan worksheet seperti word, excel, dan imagery processing seperti paint, photoshop, dan lain-lain untuk membantu proses penyediaan informasi.

Data RAW citra MODIS diambil dari Parepare atau Rumpin, Kemudian diolah untuk menghasilkan data hotspot dengan menggunakan MOD14 dan Hierarchical Data Format (HDF). Selanjutnya data HDF diolah dengan Modis swath Tool untuk menghasilkan band 1 (Red) dan band 2 (Nir) dari data HDF $250 \mathrm{~m}$, kemudian band 3 (Blue) dan band 4 (Green), band 5 (Swir), band 6 (Swir), dan band 7 (Swir) dari HDF 500m.

Setelah didapatkan band 1 sampai dengan band 7 , selanjutnya di proses di Er Mapper untuk menggabungkan band-band tersebut agar dapat mempermudah pencarian titik api (hotspot). Band yang digunakan dalam tanggap darurat ini adalah band 3, band 2, dan band 7 . Hasil olah cira satelit dari Er Mapper lalu dikompress dengan ukuran 1:5 akan menghasilkan data enhanced Compression Wavelet (ECW), dilanjutkan bagian layout dengan perkiraan koordinat titik panas atau hotspot. Hasil layout akan didiseminasikan melalui WebGIS dengan menggunakan aplikasi Geonode.

\subsection{Metode Aplikasi WebGIS}

Pengembangan Aplikasi ini dilakukan dengan Prototyping Development Metodology With Open Source Software(12). Ada beberapa tahapan yang dilakukan dalam pengembangan aplikasi web sistem informasi geografi ini, yaitu: 1) Mendeifinisikan sistem - pengembangan aplikasi WebGIS dan pengaturan pengitegrasian dan penyajian visualisasi spasial dinamis informasi sebaran titik panas; 2) Membangun prototipe - kegiatan ini dimaksudkan untuk mengembangankan prototipe yang telah didefinisikan dengan melalukan installed, configured dan customize; 3) Menentukan dan mempopulasi informasi - set informasi yang digunakan berupa informasi sebaran titik panas serta mengintegrasikan ke dalam aplikasi WebGIS; 4) Uji dan evaluasi - kegiatan ini dilakukan untuk memastikan semua fungsi pada sistem tersedia dan berjalan sesuai yang diharapkan; 5) Operasi dan dukungan sistem -
Aplikasi WebGIS memasuki tahap operasional dan dukungan. Selama beroperasi aplikasi WebGIS perlu dukungan berupa pemeliharaan.

\section{HASIL DAN PEMBAHASAN}

Penerapan aplikasi Geonode dalam rangka membangun WebGIS telah menyajikan informasi spasial dan dokumen yang terkait dengan kegiatan operasional dan litbang pemanfaatan penginderaan jauh yang dilaksanakan di unit kerja Pusfatja LAPAN. Implementasi Layer Basis Data-Spasial DBMS menggunakan perangkat lunak PostGis ${ }^{(13,14)}$ atau tata kelola data raster dalam format GeoTiff dan data vektor dalam format shapefile.

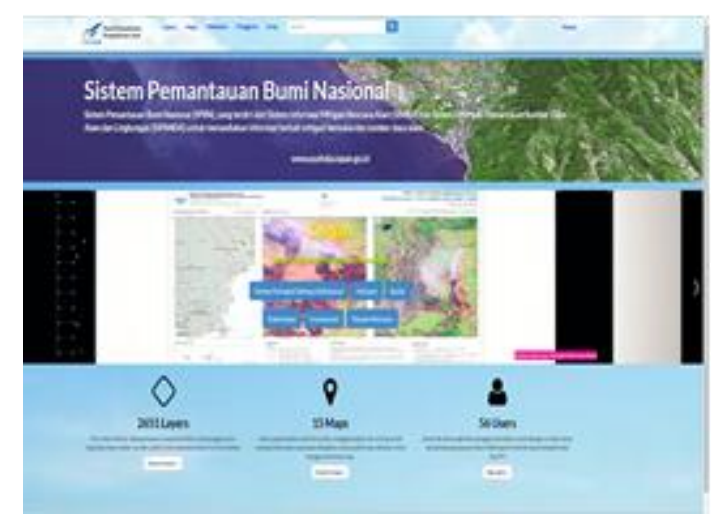

Gambar 2. Tampilan halaman muka WebGIS

Pengguna dapat mengakses informasi sebaran titik panas online melalui perambah web dalam situs web resmi http://spbn.pusfatja.lapan.go.id. Informasi spasial terdapat dalam layer, peta tematik dalam bentuk Map, serta beberapa dokumen yang terhimpun dalam menu Dokumen yang terdapat di bagian head menu website. Selain itu juga terdapat informasi tentang user/pengguna yang sudah mempunyai akun/username. Berikut ini tampilan halaman muka WebGIS yang telah dibangun.

\subsection{Layer}

Layer adalah Komponen utama Geonode. Layer adalah sumber daya publikasi yang mewakili sumber data spasial baik berbentuk data raster atau data vektor. Layer juga dapat diasosiasikan dengan metadata, penilaian, dan komentar. Dengan mengklik link Layer, kita akan mendapatkan daftar nama layer yang dipublikasikan.

Layer ini dikelompokkan menurut kategori tertentu yang meliputi: Climatology Meteorology Atmosphere, Elevation, Environment, Farming, Location, Oceans. Layer-layer ini berisi hasil ekstraksi informasi dari citra satelit penginderaan jauh yang sudah dikenal luas pemanfaatannya oleh masyarakat. 


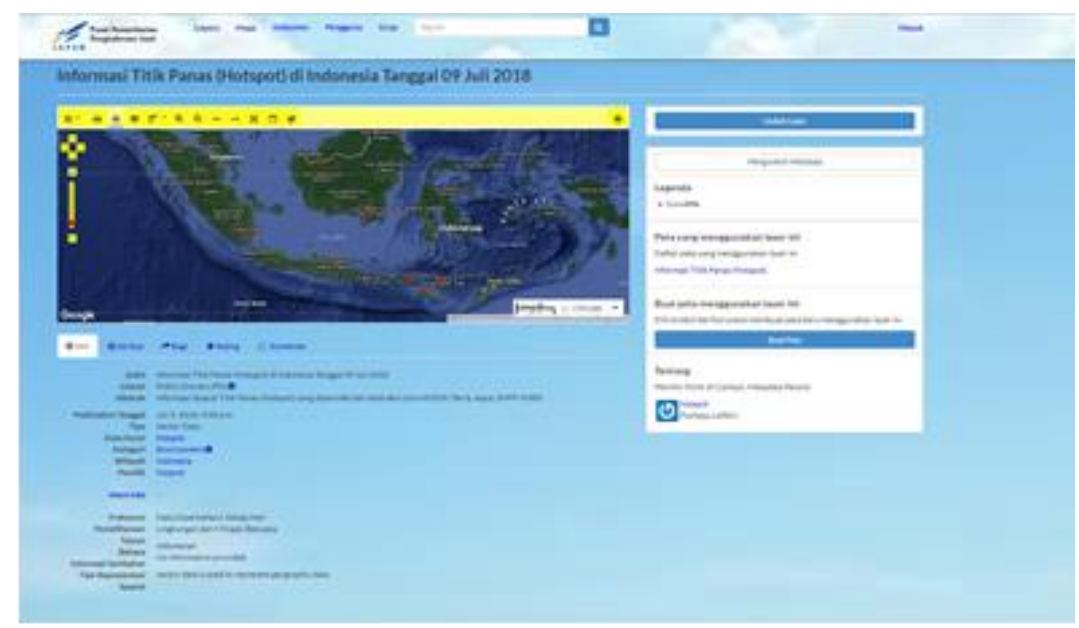

Gambar 3. Layer informasi sebaran titik panas

\subsection{Map}

Map (Peta) adalah salah satu komponen utama Geonode. Map terdiri dari berbagai Layer dan style/Legenda layer tersebut. Layer dapat berupa data spasial yang terdapat dalam server lokal di Geonode maupun data spasial yang berasal dari server di luar Geonode yang dilayani dari server WMS (Web Map Services) lainnya atau oleh layer layanan web seperti Google atau MapQuest. WMS merupakan bagian dari standar Open Geospasial Consortium yang mengatur pengiriman hasil data olahan untuk user melalui tools. Dengan menklik link map, kita akan mendapat daftar semua peta yang telah terpublikasi.

Pada tulisan ini kami batasi pada layer yang berisi informasi sebaran titik panas (Hotspot). Di bawah ini contoh tampilan layer sebaran titik panas.

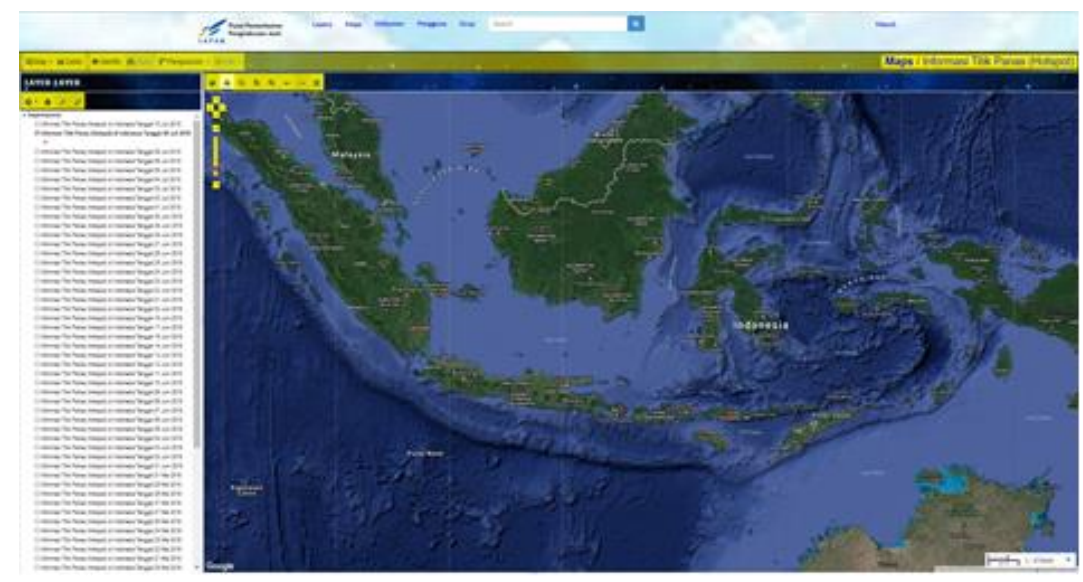

Gambar 4. Map informasi sebaran titik panas

Peta dapat dibuat berdasarkan layer-layer yang diunggah, menggabungkannya dengan beberapa layer yang ada dan layer yang berasal dari layanan web, lalu membagikan peta yang dihasilkan untuk tampilan publik. Gambar 4 contoh tampilan pet sebaran titik panas. Peta pada gambar 4 dibuat dari layer-layer sebaran titik panas. Dalam peta tersebut dapat berisi layer-layer informasi sebaran titik panas perhari, perbulan atau pertahun tergantung pada kita. Pusfatja LAPAN menampilkan informasi sebaran titik panas setiap hari.
Pada tampilan Map ada sejumlah fasilitas /tools antara lain fasilitas berdasarakan export map kedalam file gambar atau html; fasilitas untuk mencetak peta; fasilitas untuk identifikasi objek layer berdasarkan tabel atribut; fasilitas untuk melakukan Query berdasarkan tabel atribut; fasilitas untuk mengukur jarak dan luasan;

WMap - BCetak ( I Identify h Query 『Pengukuran - GEdit .

Gambar 5. Fasilitas/Tools dalam Map 
Jika kita klik ${ }^{\mathbf{\theta} \text { Identify }}$ dan klik salah satu dari titik hotspot maka akan tampil informasi seperti gambar di bawah ini.

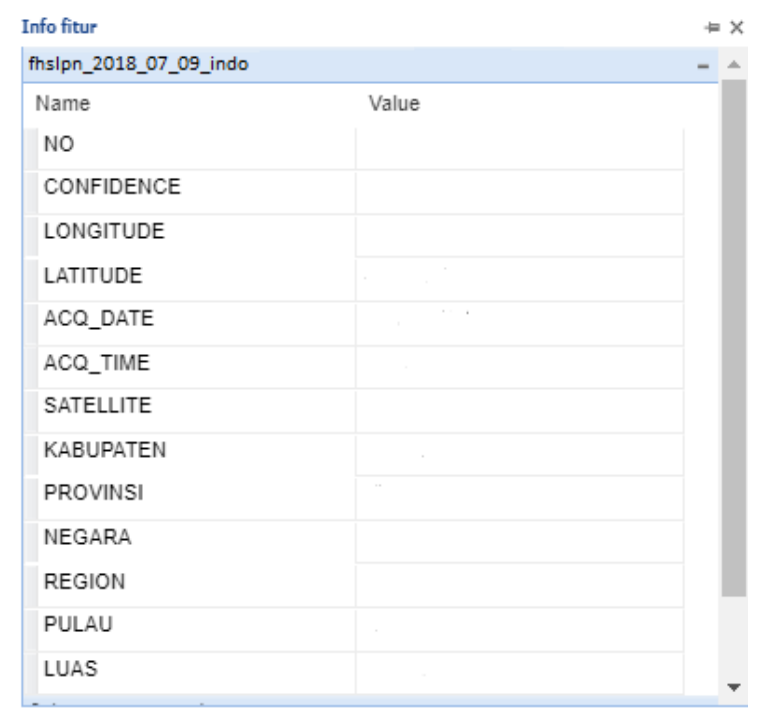

Gambar 6. Informasi yang ada dalam titik Hotspot

\subsection{Aplikasi bidang pengelolaan lingkungan}

Aplikasi Geonode yang telah diterapkan dalam Sistem Penyajian informasi sebaran titik panas telah banyak memuat informasi terkait dengan pengelolaan lingkungan antara lain informasi tentang sebaran titik panas dan area bekas terbakar, informasi peringkat bahaya kebakaran hutan, informasi curah hujan dan kekeringan, informasi potensi banjir. Kesemua itu merupakan informasi yang diekstraksi dari data satelit penginderaan jauh yang kemudian diaplikasikan di bidang lingkungan dan mitigasi bencana. Informasi tersebut dapat secara bebas diunduh oleh para pengguna di situs https://spbn.pusfatja.lapan.go.id. Selain itu system Geonode yang ada pada Sistem Penyajian informasi juga menyediakan Web Map Services (WMS) yang memudahkan pengguna untuk menghubungkan secara langsung perangkat GIS mereka dengan data/informasi yang ada pada Sistem. Link dari WMS tersebut adalah https://spbn.pusfatja.lapan.go.id/geoserver/wms ?. Dengan terhubungnya perangkat Desktop GIS dengan WMS tersebut maka pengguna bisa memanfaatkan informasi terkait pengelolaan lingkungan yang disesuaikan dengan keperluan mereka.

\section{KESIMPULAN}

Penerapan Aplikasi Geonode dalam membangun WebSIG di Pusfatja LAPAN telah mendiseminasikan informasi spasial dan tekstual hasil-hasil pemanfaatan penginderaan jauh yang dilaksanakan oleh Pusfatja LAPAN.
Sistem ini mengintegrasikan semua hasil informasi pemanfaatan penginderaan jauh dan memberikan kemudahan akses yang terjangkau secara luas oleh masyarakat pengguna.

Pengguna secara mudah dapat menerapkan penyajian visualisasi spasial dinamis, menjalankan fungsi-fungsi operasi pemetaan web dan analisis spasial informasi sebaran titik panas (hotspot) untuk mendukung dan mewujudkan kesiapsiagaan dan tanggap darurat bencana kebakaran hutan dan lahan di Indonesia.

Pemanfaatan sistem Geonode yang berbasis Open Source ini memungkinkan para penggunanya untuk berkreasi dan berinovasi dalam memodifikasi sistem sesuai dengan keperluan dan ciri khas masing-masing. Diharapkan sistem ini bisa menjembatani antara pengguna yang berkepentingan terutama dalam lingkup pemanfaatan penginderaan jauh nasional.

\section{PERSANTUNAN}

Ucapan terima kasih kami tunjukan kepada tim perekayasa serta tim bidang diseminasi Pusfatja LAPAN yang telah membantu terwujudnya penerapan GeoNode pada sistem WebSIG. Juga kepada kepala Pusat Pemanfaatan Penginderaan Jauh yang selama ini memberikan dukungan, kerja sama dan kebersamaan dalam pelaksanaan kegiatan ini.

\section{DAFTAR PUSTAKA}

1. Cristofori, E. I., Balbo, S., Camaro, W., Pasquali, P., Boccardo, P., \& Demarchi, A., (2015). Flood Risk Web Mapping For Decision Makers: A Service Proposal Based On Satellite- Derived Precipitation Analysis and Geonode. International Geoscience and Remote Sensing Symposium 2015, doi : 10.1109/IGARSS.2015.7326036.

2. Marison, G. (2015). Kebakaran Hutan dan Kejahatan Korporasi. Cited in : http://nasional.kompas.com/read/2015/10/03/1 6191531/kebakaran.Hutan.dan.Kejahatan.Kor porasi. [19 September 2015].

3. Wishnu, S. (2015). Asap Lagi, Asap Lagi Cited

http://www.kompasiana.com/wishnubio/asaplagi-asap-lagi 5609995463 afbd400ca7d8ac. [29 September 2015].

4. LAPAN. (2013). Dukungan Teknologi Penginderaan Jauh dalam Penilaian Sumberdaya Hutan (Forest Resource Assessment) Tingkat Nasional: Akses Citra Satelit, Penggunaan Kepentingan Cited in http://www.forda- 
mof.org//files/Dukungan Teknologi penginder aan Jauh LAPAN.pdf. [09 September 2013].

5. Willmes, C., Yener, Y., Gilgenberg, A., \& Bareth. G. (2016). CRC806-Database: Integrating Typo3 with Geonode and CKAN. Proceedings of the $2^{\text {nd }}$ Data Management Workshop Kolner Geographische Arbeiten, 115-126.

6. Aditya, T., \& Kraak. M. (2011). Reengineering The Goeportal: Applying $\mathrm{HCL}$ and Geovisualization Disclipines, diunduh 6 September 2017 dari www.ecgis.org/Workshop/11ecgis/papers3015aditya.pdf.

7. Hazzaard, E. (2011). Open Layer 2.10 Begineer's Guide", UK., Packt Publishing.

8. Pickle, E. (2010), Geonode: A New Approach to Developing SDI. In: CAR, A., Griesebner, G. \& Strobl, J. (Eds), Geospasial Crossroads @ Gl Forum'10. Proceeding of Geoinformatics Forum Salzburg 2010.

9. Panidi, E. (2015). Service-Based Approach to Geoportal Architecture (2015). East African
Journal of Science and Technology, Vol.5, Issue 1.

10. Reference documentation, (2017). http://Geonode.readthedocs.io/en/master/refer ence/index.html.

11. Mehdi, S. A., Ali, M., Nima, G., Zahra, R., Reyhaneh, S., \& Peyman, B., (2014). How to Implement a Governmental Open Source Geoportal. Journal Of Geographic Information System, 6, 275-285.

12. Brian, N. H. (2005). "Open source software, web services, and internet-based geographic information System Development:, http://cartogis.org/docs/proceedings/2005.

13. PostGis, (2016). PostGis 2.0 Manual, http://postgis.net/docs/manual-2.0/, (Maret 2016).

14. Obe, R., \& Hsu, E. (2011). PostGIS in Action, USA, Manning Publishing 
